\title{
Comunicación digital entre ediles y usuarios en Twitter. Oportunidad fallida en el fortalecimiento de imagen y vigencia en la esfera pública*
}

\author{
[Versión en Castellano]
}

Digital Communication Between Councilors and Users on Twitter. Failed Opportunity to Strengthen Image and Validity in the Public Sphere

Comunicação digital entre ediles e usuários no Twitter. Oportunidade falhada no fortalecimento da imagem e validade na esfera pública

Recibido el 15 de junio, 2019. Aceptado el 29 de abril, 2020.

> Para citar este artículo:

Bohórquez-Pereira, Giovanni;

Flórez-Quintero, Juan-Diego;

Alguero-Montaño, Miguel-

Orlando (2021). Comunicación

digital entre ediles y usuarios

en Twitter. Oportunidad fallida

en el fortalecimiento de imagen

y vigencia en la esfera pública.

Ánfora, 28(50), 183-214.

https://doi.org/10.30854/anfv28.n50.2021.786

Universidad Autónoma de

Manizales. ISSN 0121-6538/

e-ISSN 2248-6941.

CC BY-NC-SA 4.0
Giovanni Bohórquez-Pereira** https://orcid.org/0000-0001-7752-2008

Colombia

Juan-Diego Flórez-Quintero***

https://orcid.org/0000-0003-0977-5120

Colombia

Miguel-Orlando Alguero-Montaño****

https://orcid.org/0000-0003-0550-6783

Colombia
* Este artículo deriva del proyecto de investigación "Twitter como
medio de interacción política local. Estudio de caso en Concejo de
Bucaramanga", desarrollado en la Universidad Pontificia Bolivariana -
Seccional Bucaramanga (UPB) de la cual recibió financiamiento. Inició
en agosto de 2017 y culminó en abril de 2019. Los investigadores
declaran que no hubo conflicto de intereses en la ejecución del
proyecto de investigación.

** Magister en Ciencia Política, Pontificia Universidad Javeriana, sede Cali. Candidato Ph. D. Ciencia Política, Universidad del Zulia, Venezuela, Docente Asociado y Coordinador del semillero de investigación U'wa Werjayá, de la Facultad de Comunicación Social-Periodismo, Escuela de Ciencias Sociales, de la Universidad Pontificia Bolivariana Seccional Bucaramanga. Integrante del grupo de investigación TIC y Ciudadanía. Correo electrónico: giovanni.bohorquez@upb.edu.co

*** Estudiante de X Semestre de Comunicación Social-Periodismo de la Universidad Pontificia Bolivariana, UPB, sede Bucaramanga. Integrante activo del semillero de investigación U'wa Werjayá de la Facultad de Comunicación Social-Periodismo de la UPB, sede Bucaramanga. Correo electrónico: juan.florez.2016@upb.edu.co

*** Comunicador Social de la Universidad Pontificia Bolivariana, UPB, sede Bucaramanga. Periodista del diario La Patria de Manizales. Magíster en Estudios Políticos de la Universidad de Caldas. Correo electrónico: miguel.alguero@lapatria.com 


\section{Resumen}

Objetivo: determinar el uso de la red social Twitter por los concejales de Bucaramanga en su ejercicio como servidores públicos y líderes de opinión local, mediante la hipertextualidad, popularidad, interactividad, participación, multimedialidad e interacción. Metodología: se acude a la Netnografía con el uso de técnicas mixtas: entrevista semiestructurada y aplicación del Índice Global Potencial Persuasivo de Twitter. Resultados: se encontró que el Concejo en su proceso de divulgación pública utiliza un portal web, con información actualizada sobre sus actividades. Usa Facebook, Twitter y Youtube, pero sus registros de interacción y uso de multimedia son reducidos. Catorce de los diecinueve concejales tienen Twitter, tres de ellos marcan actividad y los contenidos difundidos sobre su ejercicio legislativo son limitados; el contenido multimedia publicado es bajo, igual que las respuestas e interacciones con usuarios. Conclusiones: se concluye que avanza la inmersión en la comunicación pública de las plataformas digitales y redes sociales para orientar y difundir el ejercicio político y más desde el campo legislativo, punto que ya los gobernantes locales y globales han entendido. Los concejales que participaron en esta investigación decepcionan al centrar el uso de Twitter en hablar de temas desligados de su función y pierden una gran oportunidad desde su microblogging para hacer propuestas relacionadas con las problemáticas sociales y contribuir desde su cuenta Twitter a consolidar su imagen y vigencia en la esfera pública y electoral.

Palabras-clave: Comunicación móvil; Comunicación política; Twitter; Comunidades virtuales; Etnografía virtual; Líderes políticos.

\section{Abstract}

Objective: to determine the use of the social network Twitter by the councilors of Bucaramanga as public servants and leaders of local opinion, through hyper-textuality, popularity, interactivity, participation, multimediality and interaction. Methodology: Netnography was used with mixed techniques: semi-structured interview and application of Twitter's Global index of Potential Persuasive. Results: It was found that the Council in its public dissemination process uses a website, with updated information about its activities. Facebook, Twitter and Youtube are used, but interaction and use of them are low. Fourteen of the nineteen councilors have a Twitter account, three of them are users, and the content disseminated about their legislative exercise is limited; the published media content is limited, as well as responses and interactions with users. Conclusions: It is concluded that the immersion in public communication of digital platforms and social networks is advancing to guide and disseminate politics, and more 
from the legislative field. This aspect has been already understood by local and global rulers. The councilors, who participated in this research, felt resistant towards the use of Twitter to focus on issues unrelated to their role as councilors and as such, miss a great opportunity in the use of microblogging, to make proposals related to social affairs, and to contribute from their Twitter account to consolidate their image and validity within the public and electoral sphere.

Keywords: Mobile communication; Political Communication; Twitter; Virtual communities; Virtual Ethnography; Political Leaders.

\section{Resumo}

Objetivo: determinar a utilização da rede social Twitter pelos vereadores de Bucaramanga em seu exercício como servidores públicos e formadores de opinião locais, através da hipertextualidade, popularidade, interatividade, participação, multimídia e interação. Metodologia: A netnografia é utilizada com o uso de técnicas mistas: entrevista semiestruturada e aplicação do Índice de Potencial Persuasivo Global do Twitter. Resultados: apurou-se que o Conselho em seu processo de divulgação pública utiliza um portal na web, com informações atualizadas sobre suas atividades. Se usa Facebook, Twitter e YouTube, mas seus registros de interação e uso de multimídia são baixos. Quatorze dos dezenove vereadores possuem Twitter, três deles marcam atividade e o conteúdo divulgado sobre o seu exercício legislativo é limitado; o conteúdo multimídia publicado é baixo, assim como as respostas e interações com os usuários. Conclusões: conclui-se que a imersão na comunicação pública das plataformas digitais e redes sociais avança para orientar e divulgar o exercício político e mais do campo legislativo, ponto que os governos locais e globais já entenderam. Os vereadores que participaram desta investigação decepcionam ao focar o uso do Twitter na conversa sobre assuntos alheios à sua função e perdem uma grande oportunidade desde o seu microblogging de fazer propostas relacionadas a problemas sociais e contribuir a partir de sua conta do Twitter para consolidar sua imagem e validade na esfera pública e eleitoral.

Palavras-chave: Comunicação móvel; Comunicação política; Twitter; Comunidades virtuais; Etnografia virtual; líderes políticos. 


\section{Introducción}

A partir de los años noventa, las formas de gobierno local en Colombia han tenido un proceso de transformación incidido por múltiples factores como los nuevos instrumentos de participación ciudadana establecidos por la Constitución Política de 1991, la descentralización de la administración pública, las reformas políticas de la participación en los partidos, la incorporación de elementos del modelo de nueva gestión pública materializados en escenarios de veeduría y la intervención ciudadana en el debate de interés general.

Sin embargo, a la par con estas transformaciones y dinámicas del accionar político nacional, regional y local, también, y de manera más rápida, las tecnologías de la información y de la comunicación han aportado a que la participación política entre a la dinámica diaria de los usuarios, así esta sea o no su tema de interés y prioridad.

Ciberpolítica, bigdata y gobierno 2.0 son temáticas que en el nuevo siglo han llamado la atención de los estudiosos de la Comunicación Política y Pública. Estos denominados ecosistemas digitales generan sociedades que buscan espacios para ejercer su derecho a participar en la política por medio de internet; las plataformas virtuales y redes sociales aportan a la creación y promoción de encuentros interactivos que garantizan la comunicación directa y multidireccional entre integrantes de una misma plataforma o comunidad.

A través de la nueva ágora digital (Cotarelo, 2013), la Ciberpolítica, por ejemplo, ofrece un clima de igualdad entre ciudadanos y gobierno. Tanto los unos, como los otros, realizan formas de comunicación que suscitan interactividad superior a las alcanzadas en décadas anteriores, donde lo personal o face to face era limitado y los mass media, eran los mediadores por excelencia para la circulación de ideas y opiniones unidireccionales. La practicidad y comodidad legitiman lo que para Maia, Gomes y Marques (2011) citados por Almeida, Alves y Miola (2014) se denomina prácticas democráticas contemporáneas.

Estas premisas sirven de base al presente artículo, que tiene como fin mostrar algunos de los resultados de la investigación Twitter como medio de interacción política local, un estudio de caso en el Concejo de Bucaramanga, que buscó dar respuesta a la pregunta: ¿cómo los ediles de una ciudad capital de Colombia establecen y realizan comunicación con sus seguidores desde Twitter? Y también indagar sobre ¿cuál es el avance de estos líderes políticos locales en el uso de los recursos que les ofrece las redes sociales digitales, RSD?

Para lograr lo trazado, en un primer momento se indagó por los procesos comunicativos al interior de la Corporación edilicia, tanto al interior, como en lo público. Luego se pasó a indagar sobre el uso que los concejales de Bucaramanga dan a las RSD desde los conceptos popularidad, participación y viralidad. El 
estudio también miró la interactividad de los corporados locales desde lo mensajes emitidos en sus cuentas y buscó verificar la gestión y la transparencia de las actividades que realizan, a partir de los contenidos publicados en sus perfiles de Twitter.

De conformidad con lo planteado por Gutiérrez-Rubí (2015) las RSD son plataformas de interacción directa entre usuarios, donde los debates ideológicos son una constante y la intensidad y profundidad dependerá en parte de quienes lideren o motiven la discusión. De ahí que para el líder político de hoy, la virtualidad es un escenario propicio para su accionar y visibilización.

Sin embargo, no todos los involucrados en campo de lo político enfrentan estos retos de la misma manera, ni con la misma disposición. Para algunos, en particular aquellos que residen en zonas donde la conectividad y formación digital es mínima, lo virtual es considerado poco efectivo y de baja credibilidad, mientras que en lugares de mayor conexión y dominio los efectos son reflejados en tendencias y replicados por otros medios.

Esta situación ha llevado a que los dirigentes políticos, tanto de orden mundial como local, se apoyen en las plataformas digitales para informar y difundir sus ideas y al mismo tiempo dichos mecanismos los hacen visible ante electores y potenciales votantes, quienes pueden acceder a él directamente para solicitar gestión, reclamarle posición sobre una situación particular y también criticarlo por su actuación o comportamiento.

En tal sentido, Castells (2012) llamó a esto la nueva democracia, pues ante la desesperanza, Internet logra que “...la gente gestione colectivamente su vida de acuerdo con los principios democráticos compartidos y que a menudo se olvidan en la experiencia cotidiana" (Castells, 2012, p. 807).

Desde otra perspectiva, Cavadas-Gormaz (2016) indica que el líder político debe saber comunicar y hacer que sus palabras conecten y hagan que el ciudadano deba ser considerado "uno de los nuestros". Por su parte, Erizalde y Riorda (2013), retoman a Mizrahi (1999), para recordar que el líder o gobernante debe demostrar en todo momento que hace bien las cosas y que "lo hace mejor que la oposición" (p. 8).

Lo anterior puede leerse como el Deber Ser de un país constituido y soportado en la democracia participativa y representativa; pero, ante las adversidades sociales y políticas, como es el caso de Colombia, se hace indispensable registrar las dos caras de la moneda. Por un lado, exponer desde lo teórico lo importante de la virtualidad en los procesos de comunicación pública y, por el otro, mostrar cómo los concejales de una ciudad capital colombiana, utilizan las TIC en su actividad pública.

En sus estudios Izureta, Arterton y Perina (2009), Zamora (2011), Peña, Pacheco y Martínez (2012), Erizalde y Riorda (2013) y Vega (2009) han señalado 
la importancia de la comunicación en el ejercicio de la actividad pública de los gobernantes y líderes políticos, la cual contribuye a legitimar la gestión:

La comunicación pública no se interesa por todo a lo que se le da visibilidad en la plaza pública, sino, esencialmente, por aquello que va a contribuir en la formación de la opinión pública y en las eventuales decisiones y acciones gubernamentales y estatales (Habermas, 1978; citado por Demers y Lavigne, (2007, p. 73).

Los representantes del Departamento de Información y Comunicación, DIC, de la Universidad de Quebec, Canadá, definieron la Comunicación Pública, $\mathrm{CP}$ como "el conjunto de los fenómenos de producción, tratamiento, difusión y de retroacción de la información que crea, orienta y transforma los debates y temas públicos” (Demers y Lavigne, 2007, p. 67).

Y pese a que los autores no desarrollan lo relacionado a las Tic y sus efectos en la CP, manifiestan que estos nuevos medios dinamizan las interrelaciones de gobernantes y ciudadanos, porque la web permite "a los individuos introducirse al debate público” (Demers y Lavigne, 2007, p. 71).

Por su parte, Vega (2009) amplía el concepto y denominará la Comunicación Política Gubernamental, CPG, “al conjunto de recursos técnicos y humanos organizados y destinados a realizar funciones informativas y periodísticas, capaces de contribuir a una correcta transparencia y publicidad en la ejecución de la política pública” (Vega, 2009, p.138).

Con lo registrado se valida que la relación gobernantes-ciudadanos pasó de distante y arrogante, (por parte del primero) y desinterés mayúsculo de la función pública (por parte del segundo), a terrenos de horizontalidad e interacción permanente de los dos (gobernantes-ciudadanos) por la mediación de las TIC, en particular la Internet y sus diversas plataformas, lográndose así la "escucha activa” (Noguera-Vivo, 2013, p. 105).

Lo anterior ha sido construido y orientado hacía el gobernante, pero ¿un edil o concejal también vivencia esta situación? Pues, desde la Constitución de Colombia de 1991 (Corte Constitucional, 2015) se afirma que sí, dado que el corporado se desempeña "como co-administrador de la Administración Municipal, que ejerce funciones de control político, conformada por concejales elegidos de forma directa por la población residente en la jurisdicción de cada municipio" (Manrique, 1995, p. 97).

Además, estudios como los hechos por Ramírez y Tabares (2011) establecen y confirman la existencia de cuatro tipos de relacionamientos entre concejales y comunidad: cooperación, intermediación, competencia y ausencia.

La investigación realizada por Bohórquez-Pereira y Alguero-Montaño (2018) demostró la presencia de dos de ellos: cooperación y ausencia. Para los 
ediles, dice el estudio, hay retroalimentación mediante sus canales de comunicación, con las que aseguran lograr cooperación. Por su parte los líderes comunales desconocen dichos contactos y "perciben a los concejales como simples líderes políticos que representan sus ideales e intereses particulares y no fortalecen la gobernabilidad ni la gobernanza en red" (Bohórquez-Pereira y Alguero-Montaño, 2018, p. 57).

Ahora bien, la entrada de Internet y demás componentes tecnológicos al mundo de lo político, llevó a la masificación de las ideas y, al mismo tiempo, a la difusa relación entre estas, los pensamientos y la imagen. Bonelly (2011) señala que desde el marketing es importante conocer a qué tipo de usuario se quiere llegar y esta premisa incluye el mundo de lo político, particularmente en procesos electorales. Luego del MyBO o fenómeno "Obama presidente" en el 2008, se comprendió "que cada individuo es capaz de impactar en una huella social que puede generar el crecimiento viral de un mensaje, un chiste, un negocio y por qué no, una campaña electoral” (Bonelly, 2011, p. 24).

El potencial que tienen estas plataformas virtuales es aprovechado por todos los que tenga el acceso a ella. No se requiere ya de grandes conexiones y equipos, ni la edad, ni el nivel educativo es limitante. Un simple click en el móvil, Tablet o PC personal, permite su entrada y navegación al mundo virtual. Ese uso creciente de estas plataformas ha originado fenómenos digitales como la viralidad en redes sociales, entendida como la hiperactividad digital por parte de los usuarios en la aceleración de los flujos y contenidos, desbordando los paradigmas tradicionales sobre emisor-canal-receptor (Gutiérrez-Rubí, 2015).

Es complejo establecer con exactitud cifras relacionadas con el mundo virtual. We are Social y Hootsuite (2019), asegura que el incremento de usuarios activos de social media, aumentó entre enero de 2018 a enero de 2019 en un 9\%. En cifras quiere decir que se pasó de 3.196 millones de usuarios a 3.484 millones, de los cuales 3.260 millones usan el móvil como medio para conectarse a redes sociales.

El informe indica que a enero de 2019 en las Américas, la actividad de las social media tuvo una penetración de $66 \%$ representado en 673 millones de usuarios, $3.8 \%$ más que el año anterior.

En lo relacionado a la red social Twitter, el informe reafirma datos ya dicho por Kit (2016), Morrison (2015) y Kamps (2015). Uno de ellos, es la incógnita del número oficial de cuentas de Twitter. En 2016, Smith Kit afirmó que Twitter tenía mil 300 millones de cuentas y calculaba que cada mes se unían o visitaban 310 millones de usuarios. Para diciembre de 2018, el informe de We are Social y Hootsuite (2019) indica que 670 millones de visitantes estuvieron en Twitter. com, por más de 9 minutos en cada visita y Omnicore Agency (2019) asegura que Twitter puede manejar 18 quintillones de cuentas de usuarios, que el $80 \%$ de 
la actividad en esta red se hace desde móvil, que el 74\% de los usuarios dicen que usan la red para recibir sus noticias y que el 79\% de las cuentas están registradas fuera de Estados Unidos.

Otro punto de coincidencia entre los informes, es el relacionado a usabilidad. A Twitter se le asigna el título de plataforma influyente por las personas que en ella participan y hacen que lo escrito se siga y replique en minutos. Cantantes, deportistas, presidentes y primeros ministros, logran atraer la atención y el tráfico en la red convirtiendo el espacio virtual en escenario para el apoyo o confrontación de ideas y conceptos. Para Morrison (2015) las cuentas verificadas o prominentes pertenecen a periodistas y líderes políticos quienes tienen alto nivel de interactividad, puesto que la utilizan como herramienta de comunicación, mientras que otros grupos sociales la utilizan como medio de información.

Perfil profesional, viralidad de los mensajes emitidos, retroalimentación, posibilidad de monitoreo a seguidores y análisis de la información a partir de los retuits, me gusta y respuesta, son características que Cotarelo (2013) le otorga a esta red y la convierte en la opción para difundir planteamientos políticos e ideología.

Adicionalmente, la personalización de las informaciones dentro de dicha red contribuye a la creación de "agremiaciones con miras a formar un conjunto de alianzas y conquistar electores” (Maia et al., 2011, p. 181) o al desarrollo de comunidades virtuales, que para Castells (1999) son redes electrónicas autodefinidas de comunicación interactiva organizadas en torno a un interés o propósito compartido entendido desde el activismo hasta la militancia por internet.

Con respecto al modelo comunicativo de esta red, Orihuela (2013) indica que Twitter es asimétrico y de allí que características como brevedad, hipertextualidad, interactividad y viralidad lo hacen diferente de las demás redes. Agrega Moya (2014) que La Mención (@); El Retuit y el Hastags (\#) son particularidades propias y hacen a esta red la mejor opción para la divulgación de ideas y participación política.

En Colombia, el informe We are Social y Hootsuite (2019) indica que 34 millones de colombianos son usuarios activos de redes sociales, que representa una penetración del 68\%, 9.7\% más que el año 2018. El tiempo promedio de esta actividad durante el día es de 9 horas, de las cuales, 3 horas 31 minutos las utiliza en redes sociales, 3 horas 12 minutos para ver televisión vía streaming y 1 hora, para escuchar música. Respecto a la conexión a la red, esta se hace en mayor medida por el móvil, Deloitte Touche Tohmatsu (2019) dice que 57\% de las personas consultadas (982) usa su teléfono para revisar las redes sociales, $46 \%$ para publicar fotos en redes y “en vivo” en redes sociales registró un 18\%. 
En el ranking de Alexa's ToP Websites, Twitter en Colombia ocupa el puesto 19 en visitas con 3.2 páginas diarias a las cuales dedican en promedio de 6 minutos y que el $60 \%$ de los usuarios de internet de este país, acceden a esta red social. Señala también que el $69 \%$ de usuarios de Twitter son hombres y $31 \%$ mujeres (We are Social y Hootsuite, 2019).

El Ministerio de Tecnologías de la Información y las Comunicaciones, MinTic Colombia (2019) reporta en su web sobre Twitter, que pese a no existir datos oficiales, "la industria estima que cerca de 6 millones de colombianos usan el popular servicio, que se ha convertido en el canal predilecto por medios de comunicación, campañas políticas, deportistas, personajes de Gobierno, entre otros".

Con respecto a la ciudad de Bucaramanga, Santander, Colombia, los datos sobre número de cuentas y uso de Twitter no son precisos. Durán $(2015$, p. 57) reporta que para el 2014, la región ocupó el cuarto lugar con 4,69\% en generación de publicaciones, durante un estudio realizado por Meridean Group. La región estuvo por debajo de Cundinamarca, 20\%, Valle del Cauca, 13,39\%, y Antioquia, 11,76\%. En la muestra estudiada (920.968 publicaciones) generada por 259.620 autores, los mensajes de contenido político fueron en $1.8 \%$ hechos en Twitter y el $80 \%$ de ellos fueron textos.

Se hace entonces necesario, revisar la nueva ágora política (Castells, 2000) esta vez desde la Corporación edilicia y sus integrantes, al advertirse Twitter como herramienta de visibilización ante la esfera pública y como medio de interactividad con los usuarios.

\section{Metodología}

La investigación se desarrolló desde el enfoque cualitativo, siendo lo descriptivo su principal énfasis, y las técnicas aplicadas fueron de carácter mixto.

De acuerdo con el interés por indagar procesos comunicativos generados desde la virtualidad con componentes como: sujetos (reales o creados), etiquetas (mensajes lingüísticos y paralingüísticos), red global diversa, e interacción o respuesta instantánea, se acudió al modelo metodológico Etnografía Virtual (Kozinets, 1997,1998), Hine (2004), Del Fresno (2011), Ruiz y Aguirre, (2015) o Netnografía (Turpo, 2008), Kozinets (2006) por considerarse el más apropiado para establecer cómo los ediles (sujetos) se presentan en la virtualidad ante seguidores y usuarios (sujetos reales o creados), así como las etiquetas, mensajes, recursos multimediales y las interacciones que se producen, logrando así mostrar las "vivencias de la red" (Turpo, 2008, p. 84), objeto propio de dicha modalidad metodológica. 
Además, la revisión y análisis de lo hallado en este tipo de procesos de indagación no interfiere con las variaciones culturales de los sujetos, ya que desde Del Fresno (2011) "el mundo social debe ser estudiado en su estado natural" (p. 67). Sin embargo, en la etnografía virtual toma relevancia la construcción de significados, objetos e identidades dadas por los espacios, campos, conexiones e interacciones entre tecnología y usuarios (Hine, 2004, p. 9).

De igual manera, el modelo permite que el investigador este inmerso en el proceso, sin que con ello pierda la imparcialidad en lo que se indaga, como

Etnógrafo [podrá habitar] en una suerte de mundo intermedio, siendo simultáneamente un extraño y un nativo... [por lo que] ha de acercarse suficientemente a la cultura que estudia como para entender cómo funciona, sin dejar de mantener la distancia necesaria para dar cuenta de ella (Hine, 2004, p. 13).

Al respecto Laaksonen et al. (2017) indican los niveles de participación del investigador dentro de la etnografía:

The role of the researcher in an ethnographic setting ranges from that of outside observer to full participant (Madden, 2010). Regardless of the level of participation, the researcher commonly writes detailed field notes, which provide a so-called thick description (Geertz, 1973) of the events and practices observed. Field notes focus on documenting highly detailed and specific descriptions of the behavior and the environment, often with analysis or interpretation kept to a minimum (p. 12).

Se planteó entonces, que al estar interesados en estudiar la interactividad de los ediles en sus redes sociales, en particular en Twitter, y aceptando que este proceso requiere una mirada descriptiva en un primer momento, para luego analizar e interpretar lo hallado, fue acertado acudir al modelo de la Netnografía, "para dimensionar el papel que tienen las tecnologías como instrumentos y recursos, pero igual como mediadores en las prácticas ciberculturales que desempeñan sus usuarios” (Ruiz y Aguirre, 2015, p. 81).

En relación con las técnicas, instrumentos y herramientas de apoyo para la Etnografía Virtual, Meneses-Cabrera y Cardozo-Cardona (2014) las ubican como prácticas de e-ciencia (Cuadra, 2009), dado que están mediadas por un ordenador que hace posible aplicar una diversidad de prácticas científicas que se soportan en la infraestructura digital.

Fue así, que por medio de técnicas mixtas de recolección y análisis de datos, se desarrolló una Netnografía de carácter o tipo observacional, en la que "el in- 
vestigador no se revela a la comunidad en línea (Kozinets, 2006, p. 9), ya que esta forma distanciada y concreta permite describir las interacciones de los usuarios dentro de la comunidad virtual.

Si bien la Netnografía extiende sus formas de estudio desde múltiples métodos, enfoques y técnicas de análisis, este trabajo utilizó en sus fases de ejecución la Observación No Participante, Bitácoras de Campo, Entrevistas Estructuradas y Análisis documental, acompañadas cada una de ellas con su respectivo instrumento a fin de no perder la rigurosidad metodológica.

En ese sentido, la investigación estableció tres momentos o fases. La primera, se centró en la caracterización de la Corporación edilicia, en sus procesos comunicativos internos y externos, para ello aplicó un formato de Entrevista Estructurada al personal administrativo y community manager de la Oficina de Prensa de la corporación. Además, se realizó Observación No Participante para identificar y registrar los medios y redes sociales que el Concejo de Bucaramanga hace uso. Fichas de observación, rejillas de análisis de datos y cuestionario con preguntas abiertas se utilizaron como instrumentos en esta primera fase.

Sobre esta base y como una segunda parte de este primer momento, se procedió a la búsqueda de la información publicada de los 19 concejales haciendo énfasis en la red social Twitter, su actividad e interactividad y uso de herramientas durante el primer y tercer periodo de sesiones ordinarias del Concejo del año 2017. Seguido a ello, con el Índice Global Potencia Persuasivo de Twitter creado por Moya y Herrera (2016) con el cual se buscó establecer la actividad de los usuarios en Twitter y su posible alcance dentro del ecosistema digital de la red:

Los procesos persuasivos subyacentes a los mensajes que los dirigentes políticos emiten en Twitter -y que reciben sin intermediación- se revelan claves para el éxito de una táctica orientada a conseguir el apoyo a un determinado programa o acción política. En ese medio, el dirigente político tiene la oportunidad de desplegar sus habilidades persuasivas, reforzando su presencia en los tradicionales a la vez que presenta una imagen pública personalizada y diferenciada de la colectiva del partido al que pertenece (Moya y Herrera, 2016, p. 845).

Por ello se requiere hallar el Coeficiente de Seguimiento relacionado al flujo de mensajes que debe existir entre dos o más cuentas y Coeficiente de Comunicación que se define como "el esfuerzo que hace una cuenta para generar conversación” (Moya y Herrera, 2016, p. 848). Por medio de las características y herramientas que brinda el microblogging, como los retuits, menciones y respuestas.

Para calcular el Coeficiente de seguimiento se tiene en cuenta el producto de la sumatoria de seguidores únicos más seguidores recíprocos sobre el total de seguidores. Mientras que para hallar el coeficiente de Comunicación es necesaria 
la ecuación del Coeficiente de seguimiento multiplicada por respuestas más menciones, más la constante 1,66 (Retuits) sobre tuits básicos los cuales no generan interacciones, más respuestas, más retuits.

El rango de valoración del Coeficiente de Seguimiento debe oscilar entre 1 y 3 siendo este último el porcentaje que demuestra la totalidad de seguidores recíprocos de una cuenta. Es decir, que hay una comunicación directa y horizontal entre el titular de la cuenta y los seguidores de la misma. Se acudió el software pago www.Twitonomy.com para el registro de los datos, los cuales se jerarquizaron de mayor a menor.

Un segundo momento del proceso, se orientó a reseñar los recursos y su uso, para ello se asumieron los conceptos de Scolari (2013) sobre multimedialidad, entendida como los diversos formatos y plataformas que permite internet para publicar información; hipertextualidad, comprendida como los múltiples enlaces y conexiones que provee la web; y la interactividad, definida como la comunicación mediada por computadores. Para su registro y posterior análisis, se elaboró una rejilla matriz de Excel con los datos de los tres (3) concejales más activos.

En relación con los textos publicados en la cuenta de los ediles seleccionados, estos se contrastaron con los contenidos de las Actas del Concejo de Bucaramanga a fin de establecer qué temas de interés públicos discutidos en las sesiones de la corporación fueron replicados en sus cuentas y si generaron alguna reacción por parte de los seguidores. Rejillas de análisis fue el instrumento aplicado para esta última fase.

\section{Resultados}

La primera parte de los resultados están orientados a la comunicación corporativa y digital del Concejo de Bucaramanga, para luego mostrar el comportamiento de los ediles en redes sociales y Twitter.

Se encontró que el Concejo de Bucaramanga en el campo de la comunicación digital cuenta con el portal www.concejodebucaramanga.gov.co. En el plano principal de la página hay nueve pestañas donde se avista: Inicio, Concejo, Concejales, Comisiones, Descargas, Participación, Contratación, Oficinas y Proyectos.

Al desplegarse la ventana "Inicio", esta permite ver los registros informativos más recientes y eventos realizados. En la pestaña "Concejo" se presentan todos los aspectos relacionados con la cultura corporativa de la entidad, mientras que en "Concejales" la información principal es el nombre de cada uno de los corporados que al desplegarse de manera individual se encuentran datos personales. La página también presenta recursos multimediales. Ofrece señal en vivo 
de las sesiones plenarias y se registra la fecha de la próxima deliberación. Hay acceso al correo institucional, directorio telefónico, respuestas a la comunidad, preguntas frecuentes, rendición de cuentas, quejas y reclamos, transparencia y acceso a la información pública.

Se evidencia actualización; su interfaz es agradable visualmente y su distribución hace fácil su operatividad. Da un enlace directo a las redes sociales en las que está registrada. $\mathrm{Al}$ respecto, se indica que tres son las redes sociales que registra el Concejo de Bucaramanga. En Twitter la cuenta es @concejodebucaramanga, en Facebook Concejo.debucaramanga y en Youtube, Unconcejoparatodos.

A 30 de septiembre de 2017 la cuenta Facebook registra 7.248 seguidores, Twitter 1.905 y Youtube 53. La cuenta de Twitter de la corporación sigue 695 cuentas, había emitido 3.450 tutis, 319 estados de me gusta y 1.571 vídeos y fotos; no registra interacción (retweet), ni muestran enlaces, tampoco hipertextualidad (Tabla 1).

Tabla 1. Datos redes sociales Concejo de Bucaramanga, 30-09-2017

\begin{tabular}{c|c|c|c|c|c|}
\multicolumn{7}{c|}{ Redes sociales del Concejo de Bucaramanga } \\
\hline Twitter & @concejobucara & Facebook & $\begin{array}{c}\text { @concejo.de- } \\
\text { bucaramanga }\end{array}$ & Youtube & $\begin{array}{c}\text { CONCEJO } \\
\text { DE BUCARA- } \\
\text { MANGA }\end{array}$ \\
\hline Seguidores & 1.905 & Seguidores & 7.248 & Suscriptores & 53 \\
\hline Seguidos & 695 & $\begin{array}{c}\text { Cantidad de } \\
\text { "me gusta" de la } \\
\text { fan page }\end{array}$ & 7.272 & Videos & 132 \\
\hline Tweets & 3450 & Videos & 107 & Vistas & 11.222 \\
\hline Me gusta & 319 & Fotos & 2.561 & & \\
\hline Multimedia & $\begin{array}{c}1.571 \text { fotosy } \\
\text { videos }\end{array}$ & $\begin{array}{c}\text { Alcance máxi- } \\
\text { mo de repro- } \\
\text { ducciones }\end{array}$ & 3.070 & & \\
\hline
\end{tabular}

Fuente: elaboración propia

En la fan page de Facebook se registran 7.272 seguidores, 107 vídeos, 2.561 fotos y un alcance máximo de reproducciones del 3.070.

El canal Youtube registra 53 suscriptores, cifra baja, en contraste con las 11.222 visitas y los 132 vídeos reportados. Al reproducir los vídeos se evidencia 
que son de corta duración (2 minutos), el contenido hace relación directa con las actividades del Concejo y el número de comentarios es limitado.

Con respecto a la variable interacción, la cuenta Facebook es la que más actividad registra, sin embargo, el feedback es limitado; una posible razón es su contenido, el cual redunda sobre una misma información.

Al revisar los perfiles de los concejales desde la pestaña de la página web se evidenció el registro de correo electrónico y redes sociales: Facebook, Youtube y Twitter; de esta última, 14 de los 19 integrantes registraron cuenta (abril, 2017).

Para la fecha en mención los concejales del Partido Liberal, Jaime Andrés Beltrán Martínez,@jbeltranconcejo y Uriel Ortiz Ruíz,@UrielOrtizRuiz junto con el edil del partido Polo Democrático, Jorge Hernán Flórez Herrara, @JorgeFlorezSi, registran el mayor número de seguidores en Twitter: 2412, 2084 y 2050, respectivamente. Caso contrario ocurre con los concejales Dionicio Carrero Correa, @DionicioCC1, del Partido Liberal, Cleomedes Bello Villabona @ CleomedesBello, del Partido de la Unidad Nacional y Jhon Marcell Pinzón Rincón, @Jhonmpinzon, también del Partido Unidad Nacional, quienes registran un número de seguidores menor a los 150. El más bajo@DionicioCC1 con 58, @CleomedesBello96 y @Jhonmpinzon, 131.

Las restantes cuentas registraban 339 seguidores@Nancyrueda03 y 1044 del concejal del Partido Centro Democrático Arturo Zambrano Avellaneda, @ ArturoZambranoA.

Como aporte adicional al estudio se realizó un cuadro comparativo entre el número de votos obtenidos por el edil en las elecciones en las que fue elegido (octubre, 2018) y sus seguidores. Se evidencia la limitada relación entre uno y otro. La excepción la muestra Jorge Édgar Flórez Herrara, @JorgeFlorezSi, cuya diferencia entre votos y seguidores es de 50. Se advierte que las cuentas de las redes sociales en ocasiones no se pueden identificar con personas (Tabla 2 ). 
Tabla 2. Número de votos obtenidos y número de seguidos en Twitter de Concejales de Bucaramanga

\begin{tabular}{|c|c|c|c|c|}
\hline Concejal & $\begin{array}{l}\text { Partido al que } \\
\text { pertenece }\end{array}$ & $\begin{array}{l}\text { Número de votos obte- } \\
\text { nidos }\end{array}$ & $\begin{array}{l}\text { Seguidores } \\
\text { en Twitter }\end{array}$ & Nombre de usuario \\
\hline $\begin{array}{c}\text { Jaime An- } \\
\text { drés Beltrán } \\
\text { Martínez }\end{array}$ & Liberal & 12.837 & 2.412 & @jbeltranconcejo \\
\hline $\begin{array}{l}\text { Uriel Ortiz } \\
\text { Ruiz }\end{array}$ & Liberal & 7.590 & 2.084 & @UrielOrtizRuiz \\
\hline $\begin{array}{l}\text { Nancy } \\
\text { Elvira Lora }\end{array}$ & Liberal & 7.965 & 339 & @NancyruedaO3 \\
\hline $\begin{array}{l}\text { Dionicio } \\
\text { Carrero } \\
\text { Correa }\end{array}$ & Liberal & 6.117 & 58 & @DionicioCC1 \\
\hline $\begin{array}{l}\text { René Rodri- } \\
\text { go Garzón } \\
\text { Martínez }\end{array}$ & Liberal & 6.117 & 679 & @ReneGarzonM \\
\hline $\begin{array}{l}\text { Henry } \\
\text { Gamboa } \\
\text { Meza }\end{array}$ & Liberal & 7.623 & 393 & $\begin{array}{c}\text { @henrygamboa- } \\
\text { meza }\end{array}$ \\
\hline
\end{tabular}




\begin{tabular}{|c|c|c|c|c|}
\hline Concejal & $\begin{array}{l}\text { Partido al que } \\
\text { pertenece }\end{array}$ & $\begin{array}{l}\text { Número de votos obte- } \\
\text { nidos }\end{array}$ & $\begin{array}{l}\text { Seguidores } \\
\text { en Twitter }\end{array}$ & Nombre de usuario \\
\hline $\begin{array}{c}\text { Wilson } \\
\text { Manuel } \\
\text { Mora } \\
\text { Cadena }\end{array}$ & Liberal & 8.867 & 921 & $\begin{array}{l}\text { @WilsonMo- } \\
\text { ra8890 }\end{array}$ \\
\hline $\begin{array}{l}\text { Jhon Mar- } \\
\text { cell Pinzón } \\
\text { Rincón }\end{array}$ & $\begin{array}{l}\text { Unidad } \\
\text { Nacional }\end{array}$ & 4.361 & 131 & @Jhonmpinzon \\
\hline $\begin{array}{c}\text { Cleomedes } \\
\text { Bello Villa- } \\
\text { bona }\end{array}$ & $\begin{array}{l}\text { Unidad } \\
\text { Nacional }\end{array}$ & 3.698 & 96 & @CleomedesBello \\
\hline $\begin{array}{l}\text { Edinson } \\
\text { Fabián } \\
\text { Oviedo } \\
\text { Pinzón }\end{array}$ & $\begin{array}{l}\text { Cambio } \\
\text { Radical }\end{array}$ & 5.224 & 499 & @FabianOviedoP \\
\hline $\begin{array}{c}\text { John Jairo } \\
\text { Claro } \\
\text { Arevalo }\end{array}$ & $\begin{array}{c}\text { Alianza } \\
\text { Social } \\
\text { Indígena }\end{array}$ & 3.446 & 729 & @johnclaro \\
\hline $\begin{array}{c}\text { Arturo } \\
\text { Zambrano } \\
\text { Avellaneda }\end{array}$ & $\begin{array}{c}\text { Centro } \\
\text { Democrático }\end{array}$ & 3.645 & 1.044 & $\begin{array}{c}\text { @ArturoZambra- } \\
\text { noA }\end{array}$ \\
\hline
\end{tabular}




\begin{tabular}{c|c|c|c|c|} 
Concejal & $\begin{array}{c}\text { Partido al que } \\
\text { pertenece }\end{array}$ & $\begin{array}{c}\text { Número de votos obte- } \\
\text { nidos }\end{array}$ & $\begin{array}{c}\text { Seguidores } \\
\text { en Twitter }\end{array}$ & Nombre de usuario \\
\hline $\begin{array}{c}\text { Pedro Nil- } \\
\text { son Amya } \\
\text { Martínez }\end{array}$ & $\begin{array}{c}\text { Opción } \\
\text { Ciudadana }\end{array}$ & 3.398 & 698 & @PedroNilsonConc \\
\hline $\begin{array}{c}\text { Jorge Édgar } \\
\text { Flórez He- } \\
\text { rrera }\end{array}$ & $\begin{array}{c}\text { Polo } \\
\text { Democrático }\end{array}$ & 2.099 & 2.050 & @JorgeFlorezSi \\
\hline
\end{tabular}

Fuente: elaboración propia

De otra parte, aplicadas las ecuaciones del Índice Global Potencial Persuasivo de Moya y Herrera (2016) a los 14 concejales activos en la red, se halló que el concejal de mayor Coeficiente de Seguimiento fue Wilson Manuel Mora @ WilsonMora8890 con 2,57 seguido de Uriel Ortiz Ruiz@UrielOrtizRuiz con 2,09\% y el tercero fue Jorge Édgar Flórez @JorgeFlorezSi con 1,46\%. Los más bajos fueron Arturo Zambrano @ArturoZambranoA con 1,11\%; seguido a él se encuentra Jaime Andrés Beltrán @jbeltranconcejo con 1,15\% y, por último, René Rodrigo Garzón @ReneGarzonM con 1,27\%. Se aclara que los ediles que aparecen con cero (0) en sus gráficas es porque no cumplieron con todos los datos para calcular las ecuaciones (Figura 1). 
Figura 1. Coeficiente de Seguimiento

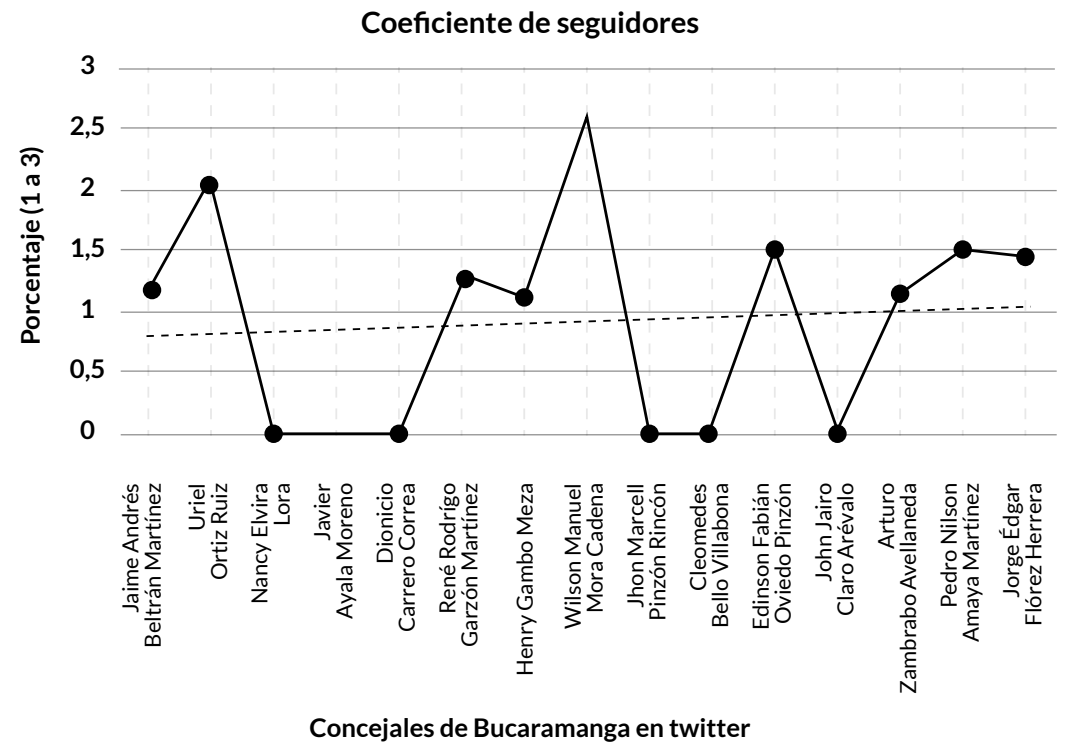

Fuente: elaboración propia

Con respecto al Coeficiente de Comunicación el resultado favoreció a Wilson Manuel Mora (@WilsonMora8890) con 13,38\% y Uriel Ortiz Ruiz (@UrielOrtizRuiz) con 7,99\%, integrantes de la bancada liberal, y a Jorge Édgar Flórez (@JorgeFlorezSi ), del Polo Democrático, con 4,73\%, quienes poseen mayor grado de actividad en Twitter. Los más bajos fueron Jaime Andrés Beltrán, @jbeltranconcejo, con 2,26\%; seguido de Edinson Fabián Oviedo, @FabianOviedoP, con 2,41\%; y, por último, René Rodrigo Garzón, @ ReneGarzonM, con 3,73\% (Figura 2). 
Figura 2. Coeficiente de Comunicación

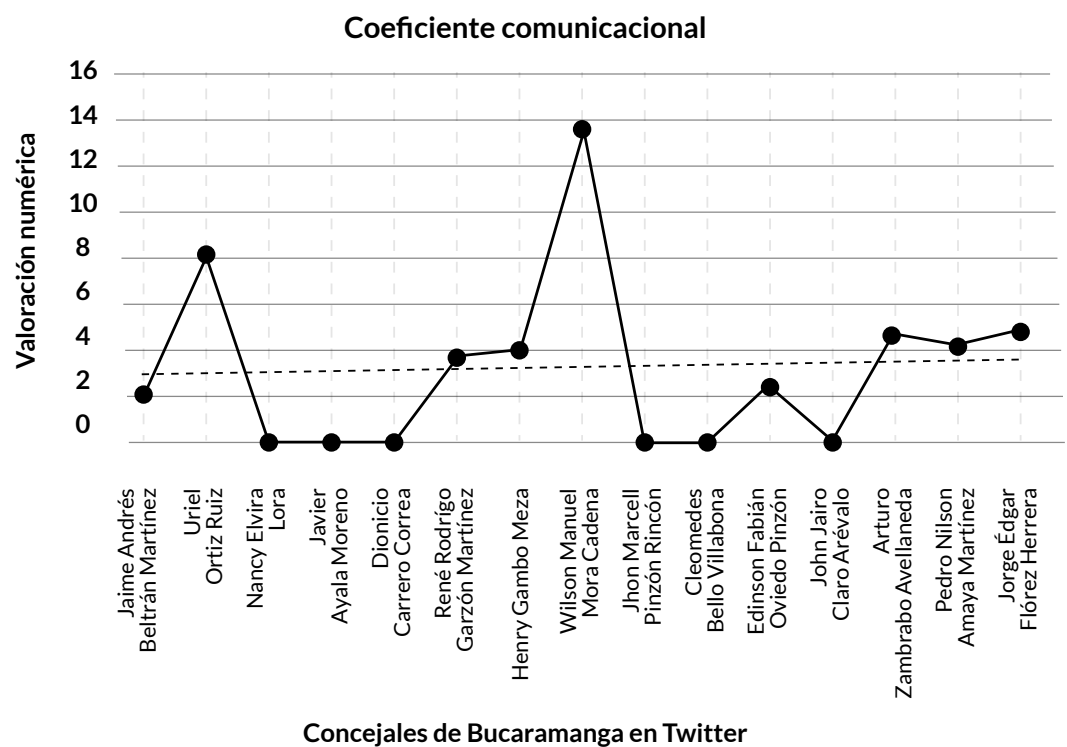

Fuente: elaboración propia

Como se indicó en la metodología los tópicos Multimedialidad, Hipertextualidad e Interactividad se aplicaron únicamente a los tres concejales de mayor Coeficiente de Seguidores y Comunicacional.

En ese orden lo que hace referencia a Multimedialidad se halló bajo uso de recursos digitales tales como imágenes, videos, audios, y formatos documentales en los tuits para el primer y tercer periodo de sesiones ordinarias de 2017. Tanto en el primero (85,48\%), como en el tercer periodo (81,88\%) de sesiones, la Multimedialidad es limitada. Quien obtuvo mayor porcentaje en ambos períodos fue el concejal Arturo Zambrano (@ArturoZambranoA), puesto que mediante el cruce de datos y la generación de las Figuras 3 y 4 es quien puntea los datos con $7,17 \%$ y $13,41 \%$ respectivamente. Mientras que Uriel Ortiz (3,94\% y 1,45\%) y Wilson Mora $(3,41 \%$ y 3,26\%), por su parte, presentan respectivamente las cifras mencionadas. 
Figura 3. Multimedialidad (primer periodo).

\section{Multimedialidad \\ (Primer periodo)}

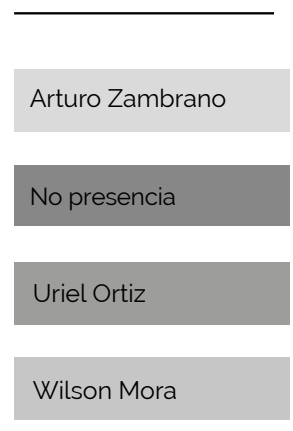

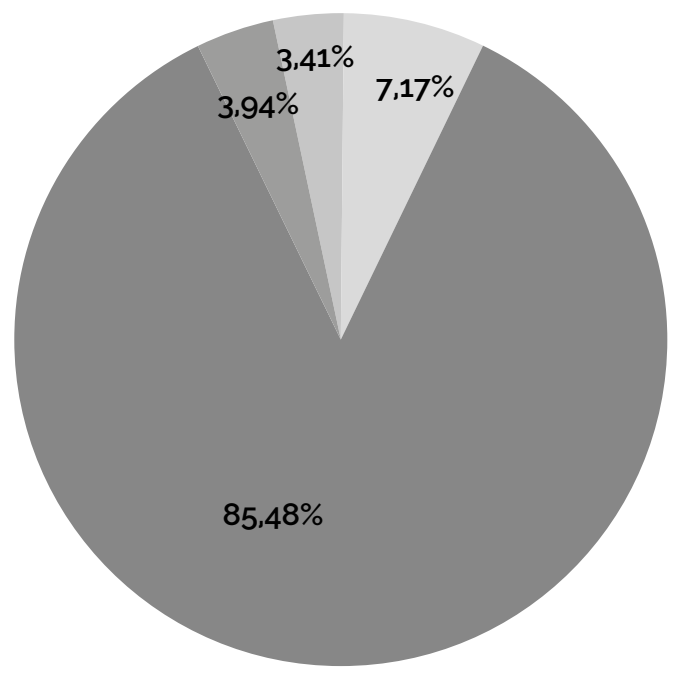

Fuente: elaboración propia

Figura 4. Multimedialidad (tercer periodo).

\section{Multimedialidad \\ (Tercer periodo)}

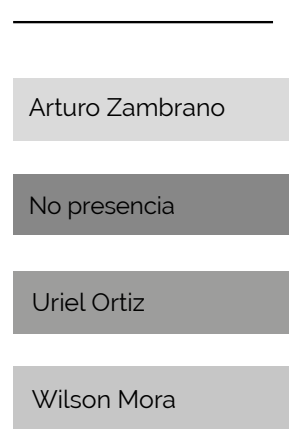

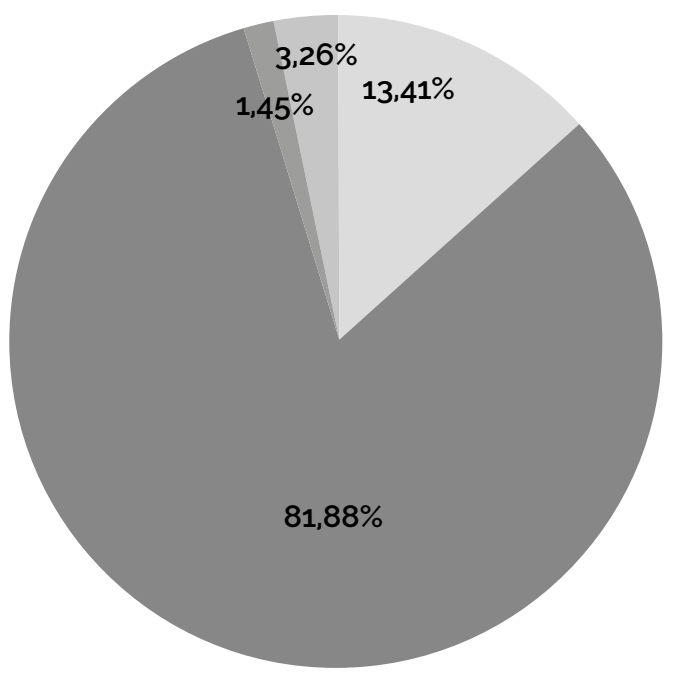

Fuente: elaboración propia 
Ahora bien, entendida la Hipertextualidad desde el uso de enlaces para ampliar información en los tuis, hasta la generación y uso de hashtags (\#), menciones(@) y retuits comentados o no por el concejal, Wilson Manuel Mora (@WilsonMora8890) obtuvo mayor porcentaje en el primer periodo (8,33\%); sin embargo, quien encabeza el rango para el tercer periodo es Arturo Zambrano (@ArturoZambranoA) (9,79\%). Frente al tercer periodo Uriel Ortiz (@UrielOrtizRuiz), obtuvo 0,91\% siendo el más bajo comparado con Arturo Zambrano (14,49\%).

Figura 5. Hipertextualidad (primer periodo).
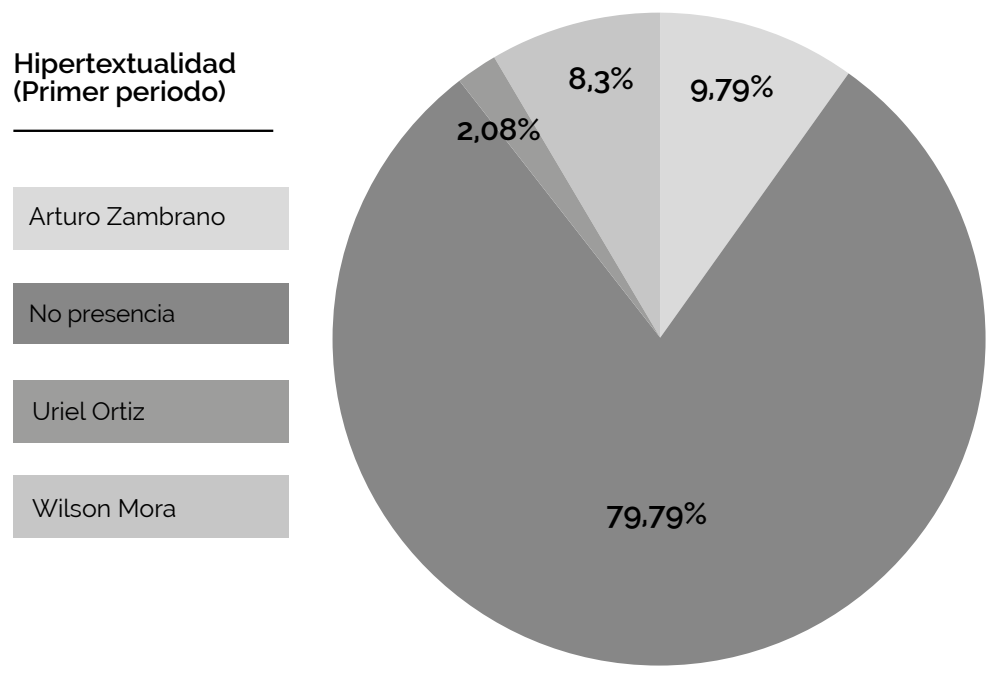

Fuente: elaboración propia 
Figura 6. Hipertextualidad (tercer periodo)
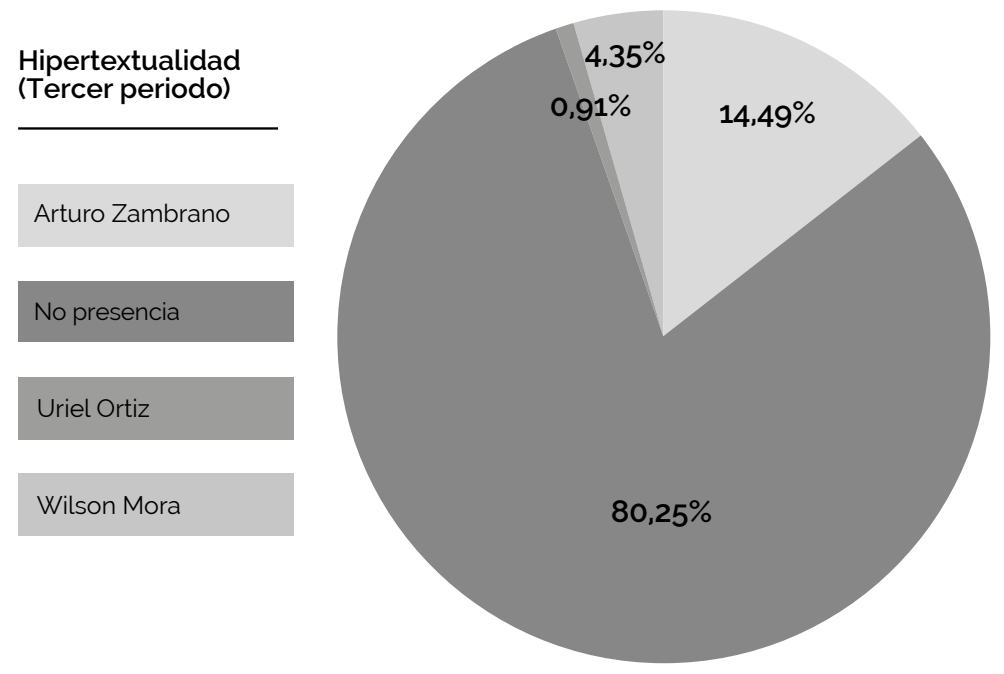

Fuente: elaboración propia

En la categoría Interactividad se buscaron los tipos de menciones, retuits y respuestas. Pueden ser colectivas, únicas, a entidades o ciudadanos digitales. En este sentido, el concejal considerado más interactivo es Arturo Zambrano (@) ArturoZambranoA), del partido Centro Democrático, con 6,58\% y 12,23\%, en cada periodo analizado. Uriel Ortiz obtuvo 5,85 y 2,17\% y Wilson Mora 4,64\% y $8,29 \%$, respectivamente. 
Figura 7. Interactividad (primer periodo).

\section{Interactividad \\ (Primer periodo)}

\section{Arturo Zambrano}

No presencia

Uriel Ortiz

Wilson Mora

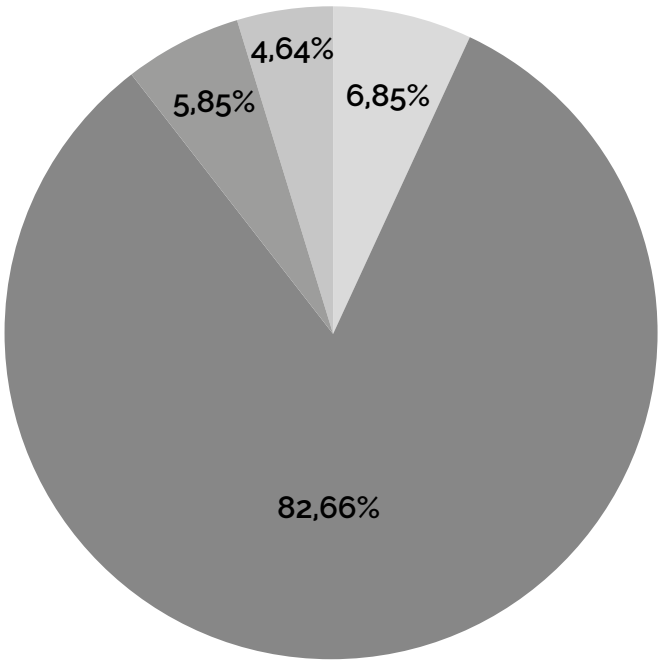

Fuente: elaboración propia

Figura 8. Interactividad (tercer periodo).
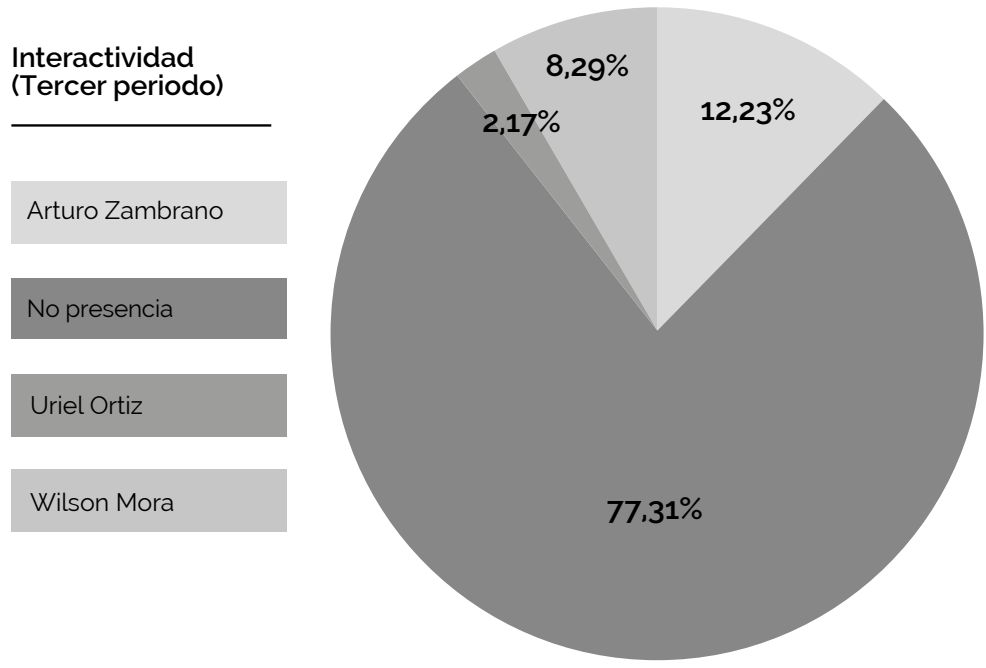

Fuente: elaboración propia 
Por último, se realizó una matriz comparativa que disponía de tuits y Actas del Concejo de Bucaramanga ${ }^{1}$; este cruce de datos se hizo de acuerdo con las fechas de los tuits publicados y las temáticas tratadas en dichos tuits respecto al tema del día en las sesiones plenarias del corporado.

Como se aprecia en la Tabla 3, menos de la mitad de las publicaciones realizadas por los concejales en esos periodos del 2017 en sus cuentas de Twitter, contienen temáticas tratadas por el Concejo de Bucaramanga.

El concejal que más se acerca al 50\% es Arturo Zambrano con 46\% en el primer periodo y $50 \%$ en el tercero. Uriel Ortiz con $21 \%$ para el primer periodo y $8 \%$ para el tercer periodo. Finalmente, Wilson Mora con $19 \%$ para el primer periodo y $5 \%$ para el tercero.

El concejal Wilson Mora (@WilsonMora8890), obtuvo el mayor puntaje en el coeficiente de comunicación, seguido por Arturo Zambrano (@ArturoZambranoA).

Tabla 3. Verificación de contenidos publicados en Twitter por los Concejales

\begin{tabular}{c|c|c|c|c|c|} 
Concejales & Verificación & Primer periodo & Promedio & $\begin{array}{c}\text { Tercer } \\
\text { periodo }\end{array}$ & Promedio \\
\hline $\begin{array}{c}\text { Wilson } \\
\text { Mora }\end{array}$ & Coincide & 11 & $19 \%$ & 2 & $5 \%$ \\
\hline No coincide & No coincide & 47 & $81 \%$ & 35 & $95 \%$ \\
\hline Uriel Ortiz & Coincide & 14 & $21 \%$ & 1 & $8 \%$ \\
\hline No coincide & No coincide & 52 & $79 \%$ & 12 & $92 \%$ \\
\hline $\begin{array}{c}\text { Arturo } \\
\text { Zambrano }\end{array}$ & Coindice & 22 & $46 \%$ & 19 & $50 \%$ \\
\hline $\begin{array}{c}\text { No coincide } \\
\text { No coincide }\end{array}$ & 26 & $54 \%$ & 19 & $50 \%$ \\
\hline
\end{tabular}

Fuente: elaboración propia 


\section{Conclusiones}

Por su tipología lo hallado en esta investigación no pretende generalizar, pero sí confirma la presencia irrefutable de los medios virtuales y en particular las redes sociales, como medio estratégico de la Comunicación Pública y Política.

Lo afirmado a través de estudios desde el lado de la rama del poder ejecutivo, como los realizados por García, López de Ayala y Fernández-Fernández (2015), Del Ruiz-Olmo y Bustos (2016), donde confirman la incidencia que tiene en el mundo virtual los textos, imágenes y demás contenidos que circulan sobre los gobernantes, sus acciones acertadas o no y la aprobación de las determinaciones que se toman, es una realidad. Esto indica que tanto el gobernante de hoy, como el líder político local y mundial, debe afrontar a diario lo que dice y cómo lo dice, además de estar preparado para recibir desde la virtualidad todos los comentarios, insultos, burlas y críticas de quiénes desde ese escenario reaccionan al contenido recibido sea este total o fraccionado.

Con las debidas y guardadas proporciones, los resultados presentados en este corto ejercicio, coinciden con Túñez y Sixto (2011) quienes advertían en su momento que "el bajo nivel de uso de las redes sociales indica que aún no se confía en el potencial que suponen como forma de contacto directo, como plataforma de visibilidad de la persona y de su gestión, como herramienta de ciberactividad, como alerta de posibles conflictos o como foro de debate" (p. 22). Al revisar y analizar los datos recolectados queda claro que los concejales de Bucaramanga, están en déficit en el manejo de redes sociales y se le debe ofertar posibilidades de formación y reducir la brecha digital que queda evidenciada. Se debe extender dicha invitación a los encargados de las oficinas de información y gabinetes de prensa de las corporaciones públicas, locales, departamentales y nacionales.

Ahora bien, en relación con el Coeficiente de Seguimiento y de Comunicación, estos dos indicadores permitieron encontrar veracidad al determinar el grado de actividad de los concejales. Además se logra confirmar la función comunicativa (Moya, 2014) que ejerce el concejal como líder político. Pese a no contar con la versión del generador del contenido (concejal), se observó que el usuario receptor (el ciudadano) siente que tiene la posibilidad de comunicación directa y, además, puede, si lo desea, alcanzar el feedback (retroalimentación) propiciado por el contenido de los mensajes que los ediles publican.

Por otro lado, los fines persuasivos son una característica fundamental de la comunicación política y, por ello, el Índice Global Potencial Persuasivo propuesto por Moya y Herrera (2016) arrojó que los retuits implican mucho más que una retransmisión del mensaje, ya que estas cascadas de difusión favorecen y potencian la comunicación, por lo que al medir la persuasión de los mensajes 
emitidos por los concejales verificamos el grado de su actividad con la eficacia que tiene su comunicación al ser respaldado por una cantidad de usuarios.

No obstante, es importante aclarar que para ampliar el alcance de la red de usuarios en Twitter es necesario que las comunicaciones entre ciber-ciudadanos y líderes políticos sea directa (Moya y Herrera, 2016), ya que en lo encontrado los concejales no tienen una comunicación real direccionada a los usuarios, puesto que dentro de la publicación de sus mensajes solo buscan difundir información y promocionar propaganda, y no crean comunidades virtuales donde sí es clara la evidencia de comunicación multimodal (Castells, 1999).

De igual forma, los concejales concentran la emisión de sus mensajes y las discusiones de los asuntos públicos con líderes de opinión dentro de la red y no democratizan sus emisiones a todos los usuarios. Por lo tanto, de acuerdo con Moya y Herrera (2016), bajo el modelo número I se analizó que A es el concejal, B es el líder de opinión y C son los ciber-ciudadanos (Ver figura 9). A y B (Modelo número II) mantienen una relación de discusión constante, mientras que C sólo es espectador de la discusión. Además, B es quien más responde a los mensajes emitidos por $\mathrm{C}$, ya que el interés de $\mathrm{A}$ es difundir información, usando erróneamente las redes sociales digitales.

Figura 9. Modelos de relacionamiento en los seguidores de Twitter

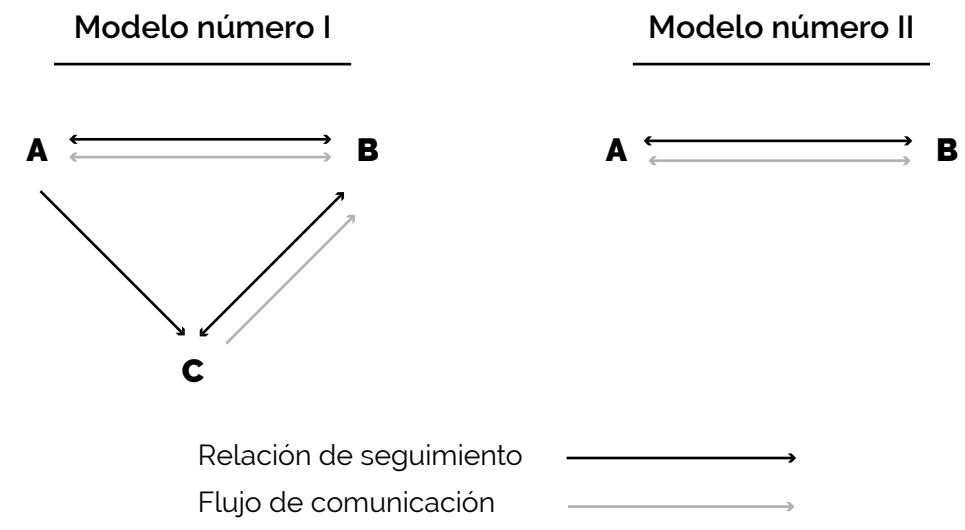

Fuente: elaboración propia

Para concretar, el actuar comunicativo de los concejales en Twitter como medio de interacción ciudadana, el uso establecido por los integrantes del corporado de utilizar sus redes personales como complemento a sus roles de líderes políticos no se está cumpliendo a cabalidad, ya que hace énfasis en la relevancia 
de su imagen, ideologías, y oposición a las administraciones locales, y no en comunicar los asuntos públicos que trata el Concejo de Bucaramanga en su accionar diario, causando desinformación al ciudadano digital.

Los resultados del uso de recursos digitales y la verificación de las agendas que publican en sus cuentas de Twitter frente a las temáticas de las sesiones plenarias es prueba de lo anterior. De los 19 concejales solo Arturo Zambrano (@ ArturoZambranoA) aprovecha las herramientas digitales que brinda Twitter y promueve la discusión de asuntos públicos por medio de comunidades virtuales.

Por su parte, los concejales Wilson Mora (@WilsonMora8890) y Uriel Ortiz Ruiz (@UrielOrtizRuiz), generan más conversaciones con diversos usuarios que Arturo Zambrano (@ArturoZambranoA). Sin embargo, estos diálogos no se orientan a difundir propuestas presentadas ante la Mesa Directiva de la Corporación o gestión realizada ante Secretarías municipales o entidades descentralizadas, sino en hacer crítica permanente al gobierno del Alcalde de Bucaramanga Rodolfo Hernández, del cual ellos son opositores.

Como todo proceso de indagación en los que se involucra la virtualidad, se requiere profundizar y ampliar tanto participantes, como técnicas de recolección de datos que dejen oír las expresiones de aquellos llamados usuarios y, también, de quienes se denominan generadores de contenido o tuiteros. Son ellos, ambos ciudadanos, ambos integrantes de una sociedad, los que deben decir si este ejercicio de interacción virtual está aportando realmente a la construcción de políticas públicas orientadas al fortalecimiento social y reducción de la desigualdad o es una forma más de dominar y someter al electorado.

\section{Referencias}

Almeida, J. A.; Alves, J. A.; Miola, E. (2014). Parlamentares, representação política e redes sociais digitais: perfis de uso do Twitter na Câmara dos Deputados. Opinião Pública, Campinas, 20(2), 178-203. https://www.scielo. $\mathrm{br} / \mathrm{pdf} / \mathrm{op} / \mathrm{v} 20 \mathrm{n} 2 / 0104-6276-\mathrm{op}-20-02-00178 . \mathrm{pdf}$

Bohórquez-Pereira, G.; Alguero-Montaño. M. O. (2018). Concejales y líderes comunitarios de Bucaramanga. Percepciones encontradas en sus relaciones comunicativas. Revista Escribanía, 16(2), 45-57. http://revistasum. umanizales.edu.co/ojs/index.php/escribania/article/view/3112 
Bonelly, R. (2011). La Huella social. Cómo los usuarios tomaron control de internet. Editorial CEC, S. A.

Castells, M. (1999). La era de la información. Alianza Editorial, S.A.S.

Castells, M. (2000). Lección inaugural del programa de doctorado sobre la sociedad de la información y el conocimiento. Universitá Oberta de Catalunya, España. https://www.uoc.edu/portal/_resources/ES/documents/la_universitat/ leccion-inaugural/leccion-inaugural-manuel-castells-2017.pdf

Castells, M. (2012). Redes de indignación y esperanza: los movimientos sociales en la era de Internet. Alianza Editorial.

Cavadas-Gormaz, M. (2016). La comunicación al servicio del líder. El caso del Ayuntamiento de Madrid. En Asociación Española Investigación de la Comunicación. En Memorias $V$ Congreso Iberoamericano de Comunicación Cultura y Cooperación (pp. 131-144).

http://www.madrid2016.org/wp-content/uploads/aeic2016 madrid_ comunicaciones_vdef_ok.pdf

Corte Constitucional de Colombia (2015). Constitución Política Colombia. https:// www.corteconstitucional.gov.co/inicio/Constitucion\%20politica\%20 de\%20Colombia\%20-\%202015.pdf

Cotarelo, R. (2013). Ciberpolítica. Las nuevas formas de acción y comunicación política. Tirant Humanidades.

Cuadra, A. (2009). Epistemocrítica de la e-Comunicación. Elementos para una etnografía virtual de las prácticas científicas en la era digital. Revista teórica del Departamento de Ciencias de la Comunicación, 13, 59-71. https://dialnet. unirioja.es/servlet/articulo? codigo $=4159233$

Deloitte Touche Tohmatsu Limited (2019). Consumo móvil en Colombia. Los cambios importantes generalmente no ocurren de la noche a la mañana. Deloite, Ed.

Del Fresno, M. (2011). Netnografía. Investigación, análisis e intervención social online. Reseña. Revista Teknokultura, 12(1), 203-210. https://revistas.ucm. es/index.php/TEKN/article/view/48898/45624 
Del Ruiz-Olmo, F. J.; Bustos. D. J. (2016). Del tweet a la fotografía, la evolución de la comunicación política en Twitter hacia la imagen. El caso del debate del estado de la nación en España (2015). Revista Latina de Comunicación Social, 71, 108-123. https://dialnet.unirioja.es/servlet/ articulo?codigo $=5346069$

Demers, F.; Lavigne, A. (2007). La comunicación pública: una prioridad contemporánea de investigación. Comunicación y Sociedad, 8, 65-87. http://www.scielo.org.mx/pdf/comso/n8/0188-252X-comso-08-65.pdf

Durán, C. A. (2015). Aspectos interventores en la participación política y electoral de jóvenes. Una reflexión sobre la información, interacción y difusión de contenidos en redes sociales para futuras investigaciones en Santander. Desafios, 27(1), 47-81. https://www.redalyc.org/articulo. oa? id $=359638976003$

Erizalde, L.; Riorda, M. (2013). Comunicación Gubernamental. Editores La Crujía.

García, C. B.; López de Ayala, M. C.; Fernández-Fernández, J. G. (2015). Twitter como plataforma de los alcaldes para la comunicación pública. Estudios sobre el Mensaje Periodístico, 21(2), 757772. https://revistas.ucm.es/index. $\mathrm{php} / \mathrm{ESMP} /$ article/view/50884

Gutiérrez-Rubí, A. (2015). La transformación digital y móvil de la comunicación política. Editorial Ariel S. A.

Hine, C. (2004). Etnografia virtual. Editorial UOC.

Izureta, R.; Arterton., C.; Perina., R. (2009). Estrategias de comunicación para gobiernos. Ediciones La Crujía.

Kamps, H. J. (2015). Who Are Twitter's Verified Users? Medium, 1-15. https:// medium.com/@Haje/who-are-twitter-s-verified-users-af976fc 1 bo32

Kit, S. (2016). 44 estadísticas de Twitter para 2016. [Entrada en un blog]. https://www.brandwatch.com/es/2016/06/44-estadisticas-twitter-2016/

Kozinets, R. (1997). I Want to Believe: A Netnography of the X-Philes' Subculture of Consumption. In M. Brucks \& D. J. Maclnnis (Eds.). Advances in Consumer Research (pp. 470-475). Assoc Consumer Research. 
Kozinets, R. (1998). On netnography: Initial Reflections on Consumer Research Investigations of Cyberculture. In J. W. Alba \& J. W. Hutchinson (Eds.). Advances in Consumer Research. (pp. 366-371). Association for Consumer Research.

Kozinets, R. (2006). Netnography 2.0. En W. Russell (Ed.). Manual de métodos de investigación cualitativa en Marketing (pp. 129-142). Edward Elgar Editorial y ONU.

Laaksonen, S. M.; Nelimarkka, M.; Tuokko, M.; Marttila, M.; Kekkonen, A.; Villi, M. (2017). Working the Fields of Big Data: Using Big-data-augmented online ethnography to study candidate-candidate interaction at election time. Journal of Information Technology \& Politics, 14(2), 110-131. https:// www.tandfonline.com/doi/abs/10.1080/19331681.2016.1266981

Maia, C. M.; Gomes, W.; Marques, J. A. (Eds.). (2011). Internet e Participação Política no Brasil. Editora Sulina.

Manrique, R. A. (1995). El municipio después de la Constitución de 1991. Empresa Editorial de Cundinamarca Antonio Nariño.

Meneses-Cabrera, T.; Cardozo Cardona, J. (2014). La Etnografía: una posibilidad metodológica para la investigación en cibercultura. Revista Encuentros, 12(2), 93-103. http://www.scielo.org.co/pdf/encu/v12n2/v12n2a07.pdf

Ministerio de las Tecnologías de Información y Comunicación de Colombia (2019). Colombia es uno de los países con más usuarios en redes sociales en la región. https://mintic.gov.co/portal/604/w3-article-2713.html?_ noredirect $=1$

Mizrahi, Y.(1999). Voto retrospectivo y desempeño gubernamental: las elecciones en el Estado de Chihuaha, México. Estudios Políticos, Documento de trabajo, 100, 1-30. http://biblioteca.clacso.edu.ar/ar/libros/lasa98/Mizrahi.pdf

Mullin, B. (2015). Report: Journalists Make Up a Quarter of All Verified Twitter Accounts Adweek. https://www.poynter.org/reporting-editing/2015/ report-journalists-are-largest-most-active-group-on-twitter/ 
Moya, M. (2014). Análisis comunicacional del uso que los diputados españoles hacen de Twitter: evaluación e implicaciones prácticas (Tesis de Doctorado). Universidad Carlos III de Madrid. https://e-archivo.uc3m.es/handle/10016/20431

Moya, M.; Herrera-Damas, S. (2016). Cómo medir el potencial persuasivo en Twitter: propuesta metodológica. Palabra Clave, 19(3), 838-867. https://palabraclave.unisabana.edu.co/index.php/palabraclave/article/ view $/ 6075 / \mathrm{html}$

Noguera-Vivo, J. M. (2013). How Open are Journalists on Twitter? Trends Towards the End-user Journalism. CommunicationङSociety/Comunicacion y Sociedad, 26(1), 93-114. https://revistas.unav.edu/index.php/ communication-and-society/article/view/36156

Omnicore Agency (2019). Twitter por números: estadísticas, datos demográficos y datos curiosos. https://www.omnicoreagency.com/twitter-statistics/

Orihuela, J. L. (2013). Mundo Twitter: una guía para comprender y dominar la plataforma que cambió la red. Alienta Editorial.

Peña, P.; Pacheco, M.; Martínez, P. (2012). Comunicación institucional y política. Editorial Fragua, Biblioteca de Ciencias de la comunicación.

Ramírez, M. F.; Tabares, J. (2011). Las relaciones entre los actores del gobierno local en el marco de la gobernanza. Una mirada desde los concejales de Medellín. Participación Política, 16(1), 213-239. http://www.scielo.org.co/ pdf/papel/v16n1/v16n1a09.pdf

Ruiz, M. R.; Aguirre, A. G. (2015). Etnografía virtual, un acercamiento al método y a sus aplicaciones. Estudios sobre las Culturas Contemporáneas, 41, 67-96. https://www.redalyc.org/pdf/316/31639397004.pdf

Scolari, C. (2013). Hipermediaciones: elementos para la teoría de una comunicación digital interactiva. GEDISA.

Túñez, M.; Sixto, J. (2011). Redes sociales, política y Compromiso 2.0: La comunicación de los diputados españoles en Facebook. Revista Latina de Comunicación Social, 66, 1-25. https://www.redalyc.org/articulo. oa? $\mathrm{id}=81921340015$ 
Turpo, O. (2008). La netnografía: un método de investigación en Internet. Revista Iberoamericana de la Educación, 42, 81-93. http://www.redalyc.org/ articulo.oa?id=342130831006

Vega, H. (2009). La comunicación de gobierno e Internet. En R. Izureta, C. Arterton \& R. Perina. (Eds.). Estrategias de comunicación para gobiernos (pp. 131-184). Ediciones La Crujía.

We Are Social y Hootsuite (2019). Global digital 2019. Global digital yearbook. https://datareportal.com/reports/digital-2019-colombia

Zamora, R. (2011). Claves para gestionar la comunicación local. Comunicación Social, ediciones y publicaciones. 